\title{
TENTATIVA DE UM DIAGNÓSTICO DE ENFERMAGEM DA FAMILIA
}

\author{
Emilia Campos* \\ Mara Helena Machado* \\ Tokico Murakawa Moriya*
}

\begin{tabular}{l|c} 
& $\mathrm{RBEn} / 02$ \\
\hline
\end{tabular}

CAMPOS, E., MACHADO, M.H. e MORTYA, T.M. - Tentativa de um diagnóstico de enfermagem da familia. Rev. Bras. Enf.; DF, 29 : 25-27, 1976

\begin{abstract}
"A enfermagem é uma clência e arte de assistir o ser humano (individuo, famillia e comunidade) no atendimento de suas necessidades básicas, de tornálo independente desta assistência, quando possível pelo ensino de auto-cuidado; de recuperar, manter e promover a saúde em colaboração com outros profissionals".
\end{abstract}

Se aceitamos o postulado acima e admitidos que as necessidades universals do ser humano são manlfestadas pelo Indivíduo de várias maneiras é indispensável que o enfermelro as identifḷ̣ue e preste a assistêncla que se flzer necessárío.

Questionamos: está o enfermelro atento a perceber e atender às necessidades básicas do ser humano quando afetadas? Em qualquer situação?

Tivemos uma experiência e achamos oportuno descrevê-la.
Durante visitas domiciliares como parte de pesquisa sobre streptococcus, nossa atenção estava dirigida apenas para o atendimento de objetivos da mesma. Entretanto, logo nas primeiras visitas demo-nos conta que ao nos apresentarmos às familias como enfermelras, estas além das Informaçōes inerentes à pesquisa de streptococcus apresentavam outros problemas de ordem física, emoclonal e/ou social. Pouco se sabe sobre o diagnóstico de enfermagem da familia, ou melhor dizendo, quals seriam as necessidades básicas da família. Esta é um todo coeso, não se constituindo da soma das caracterísitcas da personalldade de cada um de seus membros.

Embora o objetivo não tenha sido proceder ao diagnóstico de enfermagem da familia, por isso mesmo nem sequer esboçamos um histórico de enfermagem, fol possível entretanto identificar uma

- Docentes do Departamento de Enfermagem Geral e Especializada da Escola de Enfermagem de Ribeirāo Preto, USP. 
CAMPOS, E., MACHADO, M.H. e MORIYA, T.M. - Tentativa de um diagnóstico de enfermagem da familia. Rev. Bras. Enf.; DF, 29 : 25-27, 1976

série de problemas de enfermagem, manifestaçōes de necessidades humanas básicas que achamos de interesse relatar nossa experiência para estudos futuros.

Foram estudadas trinta familias cujos problemas foram agrupados como se segue:

\section{PROBLEMAS IDENTIFICADOS:}

Hipertensão.

Infecção auditiva com recidiva.

Afonia.

Implementação irregular de caninos, o paí não deixa extrair por medo de hemorragia.

Analfabetismo.

Queixas de tonturas, palidez, perda de peso, mucosas descoradas.

Desmaios.

Seis pessoas num único cômodo, 13 pessoas em dois cômodos.

Cozinha no quintal sobre tijolos.

Filha com "medo" de chuva, acha que o telhado val cair, corre pela vizinhança e ao regressar dorme na varanda da casa em frente.

Filha com antecedentes de anemia e aparente recidiva.

Marido após trauma craniano ficou nervoso, perdeu ánimo pela vida e tornou-se alcoólatra, edema do $M I$, não cuida da higiene pessoal. Nāo se alimenta só bebe cerveja, quelra-se de que a esposa nāo mals corresponde sexualmente.

Mulher considera-se doente, na menstruaçāo apresenta cefaléla durante três dias, necessitando ficar em repouso absoluto e quarto escuro.

Não tem fossa.

Lixo no quintal.

Filhos com disritmia cerebral em tratamento, nervosa.

Criança com oito meses recebendo só mamadeira.
Falta de recursos econômicos para alimentação.

Primigesta no $8 .^{\circ}$ mês pede orientação para o parto e freqüenta pré-natal do INPS.

Filha pálida, sonâmbula, a mãe a considera anormal.

Filha de 7 anos que teve encefalite, não fala, não anda.

Após A. V. C. encontrou o objetivo da vida.

Morte de uma filha excepcional de 5 anos, longe dos familiares, pai deprimido por haver consentido em separar-se da filha a quem muito queria.

Criança de 11 anos com dentição extranumerária; por informação da mãe já trocou os dentes, três vezes.

Escabiose.

Diarréla.

\section{NECESSIDADES AFETADAS:}

Sócio-Econômico.

Segurança.

Educação à Saúde.

Culdado Corporal.

Amor.

Sexualidade e Reprodução.

Nutrição.

Aprendizagem.

Integridade Física.

Terapêutica.

Oxigenaçāo.

Comunicaçāo.

Regulaçāo Neurológica.

Educaçāo à Saúde.

Espaço.

Integridade cuidado cutáneo mucosa.

Ambiente Físico.

Segurança Emocional.

Regulação Vascular.

Regulação Imunitária.

tica ou filosofia de vida.

Locomoção.

Gregária.

Eliminaçāo.

Terapêutica. 
CAMPOS, E., MACHADO, M.H. e MORIYA, T.M. - Tentativa de um diagnóstico de enfermagem da familia. Rev. Bras. Enf.; DF, $29: 25-27,1976$

\section{DISCUSSAO E CONCLUSAO}

Analisando os problemas identificados percebemos diversos tipos de necessidades às quais o enfermeiro está apto a atender. São problemas tanto sócioeconômico como emocionais ou de saúde.

Não estamos certas de quanto estamos alertas para detectar essas necessidades e assistir, principalmente quando entramos em contato com uma população supostamente sadia ou quando desenvolvemos um trabalho com algum objetivo já em mente.

Isto porque a maioria dos enfermeiros tem o hospital como local de trabalho cuja assistência de enfermagem é para o homem doente ou a nossa preocupação está apenas voltada para a realização de uma pesquisa. As enfermeiras de Saúde Pública têm assumido a responsabilidade do atendimento da saúde da comunidade. Agora no entanto, estamos começando a nos conscientizar que o ideal seria que todos fôssemos hábeis em diagnosticar problemas especificos de saúde da familia como fazemos com indivíduos.

Algumas tentativas têm sido feitas para esclarecer e definir o diagnóstico de enfermagem da família. Freeman e Lowe idealizaram uma forma para sistematizar o processo pelo qual uma enfermeira julga a competência da familia. Tapia propōe o estudo de tarefas do núcleo familiar e a habilidade da família em conseguir realizar estas tarefas.
Ela classifica a família em cinco níveis: Nível 1 - Família caótica - no estágio de desenvolvimento de criança, o mais baixo nivel caracterizado pela desorganização em todas as áreas da família. Nivel 2 - Família intermediária, estágio de infância, caracterizado por menor desorganização que o primeiro nível. Nivel 3 - Família normal com muitos conflitos e problemas, estágio de adolescente. Nível 4 - Familia com soluçōes para seus problemas - estágio adulto. Nível 5 - 0 ideal da família independente - maturidade completa. A maior ênfase do trabalho de enfermagem com a família de nível 1 é desenvolver um verdadeiro relacionamento, com uma família de nível 2 é ajudar a familia a definir problemas; família de nivel 3 requer complexa habilidade de enfermagem e a prevenção será o enfoque do trabalho com a família 4.

Todas essas tentativas de diagnóstíco de enfermagem da família serão mais efetivos quando o enfermeiro iniciar medidas de enfermagem significativas em tempo e esforço que o conduzirá ao sucesso de ajudar a familia a aumentar sua habilidade em encontrar suas necessidades.

Percebemos que se existisse um planejamento e integração em nosso trabalho, poderíamos encaminhar diversas famílias cujas necessidade sócio-econômicas eram evidentes. Limitamo-nos a encaminhar, orientar ou atender na medida do possível, às necessidades emocionais e as relacionadas com a saúde.

\section{BIBLIOGRAFIA}

FREEMAN, Ruth B. and LOWE, Marie. Method for appraising family public health nursing needs. Am. J. Public Health 53 :47-52, Jan. 1963.
HORTA, A. Wanda - Díagnóstico de Enfermagem - Rev. Bras. Enf. 4-ju!ho/set. 1972.

TAPIA, J. A. - The nursing process in $\mathrm{fa}-$ mily health - Nurs. Outlook 20(4) - April, 1972. 